LABORATORIUMS V. vereinigt mit Das Medizinische Laboratorium

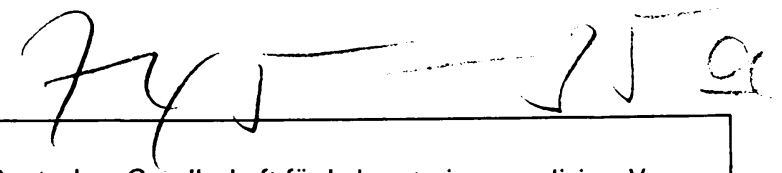

Offizielles Organ der Deutschen Gesellschaft für Laboratoriumsmedizin e.V. Offizielles Organ des Berufsverbandes Deutscher Laborärzte e.V.

Offizielles Organ der Österreichischen Gesellschaft für Laboratoriumsmedizin Offizielles Organ des Institutes für Standardisierung und Dokumentation im medizinischen Laboratorium e.V. (INSTAND e.V.)
Verlag

Kirchheim + Co GmbH

6500 Mainz
INHALTSVERZEICHNIS

10. Jahrgang, 1986

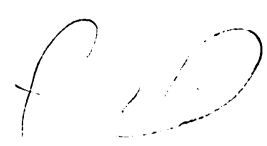

Serumkomplementfaktoren, Akute Phase Proteine und zirkulierende Immunkomplexe bei Neurodermitikern vor und nach Testmahlzeiten

G. Ionescu, D. Radovici, H. Mahal

Bestimmung der Pharmakokinetik verschiedener Benzodiazepine mit Hilfe einer Rezeptorbindungsmethode W. Sieghart, G. Drexler, B. Saletu

Neopterin, ein Marker der zellulären Immunantwort H. R. M. Lang

LONG I a - Folgeuntersuchung zur Longitudinalstudie LONG I

M. G. Weyer, H. Lommel

Die Cholesterin-Parabel und der Reigen der Sterine E. K. M. Boskamp

Bestimmung der freien und konjugierten Katecholamine mit HPLC und amperometrischer Detektion H. Weicker

Photometrische $D^{u}$-Bestimmung durch kontinuierliche Durchflußanalyse

K. Graefe, W. Gräßmann, B. Siebert

Marktübersicht und Bewertung kommerzieller Reagenzien zum Nachweis von Antikörpern gegen Parasiten

K. Janitschke, U. Senk, A. Reinhold, S. Lichy

Über eine neue Nachweistechnik von erythrozytärgebundenen Immunglobulinen bei Ouchterlony und Mancini-Immundiffusion

P. M. Winter, A. H. Niemetz

Das Sollwertermittlungsmodell des Verbandes der Diagnostica- und Diagnosticageräte-Hersteller e. V. (VDGH) - bisherige Erfahrungen

B. Müller-Wiegand, A. Benozzi, H. Brettschneider,

H. Häusler, E. Neckermann, H. Passing, R. Spaethe

Lokaltherapie von bakteriellen Ohrinfektionen W. Elies

Ein Enzym-Immuno-Test für den Nachweis von Spermatozoen-Antikörpern

K. H. Scheit, H. von der Kammer, W. Wuttke, G. Neumann, B. Hinney

Vergleichende Bestimmung des Gesamtthyroxins im Serum mit einem konventionellen Radioimmunoassay (RIA) und dem TD $_{x}$-System (FPIA)

P. Weiß, H. Fritzsche

Zum Problem der Kalibrierung von Thromboplastinen C. Montigel

Tumormarker: Empfehlungen zum sinnvollen Einsatz

L. Thomas

Atomspektrometrische Spurenanalytik - Anwendungstechnische Beispiele aus der Umwelt-Analytik

K. R. Sperling

Fehlermöglichkeit des Limulus-Amoebozyten-Lysat-Testes bei der Endotoxinbestimmung im Serum

D. Berger, H. G. Beger

Erfahrungen mit einem neuen System zur Identifizierung und MHK-Bestimmung gram-positiver Keime

\title{
T. Beringer
}

1 Urogenitale Chlamydia trachomatis-Infektionen:

Technische Aspekte der kulturellen Routinediagnostik H. Klein, H. Blenk

13 boratorium: Kalium-Bestimmungen am Ektachem ${ }^{\circledR}$ DT 60 und am Seralyzer ${ }^{\circledR}$ W. Appel

30 Jahre Deutsche Gesellschaft für Laboratoriumsmedizin

H. Reinauer

25 Zuverlässigkeit der Blutgruppenbestimmung bei Neugeborenen

E. A. Bähr, V. Kretschmer

Untersuchungen zur Stabilität von Antibiotika in festen Nährmedien in Abhängigkeit von deren Lagerzeit

U. Ullmann $\lg$, IgA und $\lg M$ am Hitachi 705 nach einem Verfahren mit 1-Punkt-Kalibrierung

M. Akita, R. Müller-Matthesius

Vergleich der minimalen Hemmkonzentration von Pseudomonas aeruginosa gegenüber Gentamichin, Tobramycin und Netilmicin in Nährböden mit und solchen ohne Kalzium-/Magnesium-Supplementierung

G. Schröter, G. Hohn-Mertesacker, G. Schaver

Neue Entwicklungen und Techniken auf dem Gebiet der Präsenzdiagnostik

L. Thomas

65 Grundlagen atomspektrometrischer Analytik G. Schlemmer, B. Welz

82 Welche analytische Methode zur Bestimmung der sauren Phosphatase (SP) beziehungsweise Prostataphosphatase (PAP) sollte im Routinelabor angewendet werden?

61 G. Oremek, U. B. Seiffert, G. Heinert, W. H. Siede, J. Rokkenbach

Wertigkeit der Direktnachweisverfahren in der Diagnostik von Chlamydieninfektionen

Die Bestimmung der $\alpha$-Amylase mit einem neuen enzymatischen Farbtest unter Verwendung des Substrates 2 Chlor-4-nitrophenyl- $\beta$-D-maltoheptaosid

\section{H. Fritze, E. Henkel}

Häufigkeit und klinischer Verlauf jodinduzierter Hyperthyreosen

N. Pocker, D. Jüngst

Immunfixations-Elektrophorese zum Nachweis monoklonaler Gammopathien: Durchführung, Interpretation Fehlermöglichkeiten

Maren Baus, T. Müller, L. Thomas 
Erprobung des Hitachi 737 Analysen-Systems bei $25^{\circ} \mathrm{C}$ F. Keller, F. Metz, J. Thiery, D. Seidel, K.-J. Knoke, R. Koberstein

Verband der Diagnostica- und Diagnostica-

Hersteller e. V.

Symposium "Nutzen, Kosten und zukünftige Entwicklung der Laboratoriumsdiagnostik"

Der VDGH und diese Tagung

R. Gallien

Die Diagnostica-Industrie: Charakteristik, Entwicklungen, Probleme

U. Aldag

Beispiele zur Kosten-Nutzen-Relation bei Laboratoriumsuntersuchungen

G. Schlicht

Laborwachstum und Kostendämpfung ein Widerspruch?

O. P. Schaefer

Labordiagnostik im Krankenhaus - Stellenwert und Überlegungen zu den Kosten

E. R. Wittermann

Monoklonale Antikörper in der Tumordiagnostik und -therapie

G. J. Hämmerling

Neue Entwicklungen und Techniken auf dem Gebiet der Präsenzdiagnostik

L. Thomas

Möglichkeiten und Grenzen der Diagnostik mit DNAProbes

H. Wolf, U. Leser, M. Motz, R. Seibl

Good Manufacturing Practice bei Herstellung und Prüfung von In-vitro-Diagnostika

W. Wöhle

Empfehlung zum Führen von Leistungsstatistiken in klinischen Laboratorien

H. Wüst

Externe Qualitätskontrolle von Pharmaka-Analysen.

Ringversuchsergebnisse 1981-1985

K. Borner, H. Reinauer

$\mathrm{Bi}$ - und triklonale Gammopathien - Klinik und

Diagnostik

R. Pudill, P. Tarkkannen

Bisherige Entwicklung und Zukunft der AIDS-Diagnostik

A. Werner, R. Kurth

Diskussion auf dem VDGH-Symposium in Frankfurt

Die Lysis-Zentrifugations-Blutkulturmethode (Isolator). Erprobung an ausgewählten Fällen von Bakteriämie und Sepsis

G. Huber, G. Hoffbauer, G. Ruckdeschel, J. Holl, T. Sauerbruch

Ein einfacher Kryptosporidiennachweis im Rahmen der parasitologischen Stuhl-Routinediagnostik

P. Kimmig, S. Hartmann

Photometrische Fibrinogenbestimmung mit einem kinetischen Trübungstest

A. Dessauer, E. Spanuth, K. Bartl

Serologische Diagnostik von Influenza A- und B- Infektionen mit Hilfe der Komplementbindungsreaktion und der indirekten Immunfluoreszenztechnik

G. Döller, P. C. Döller, H.-J. Gerth

Serologische Diagnose von Coxiella burnetii-Infektionen:

ELISA zum Nachweis von IgM- und IgA-Antikörpern und

KBR mit Phase I- und Phase II-Antigen mit besonderer

Berücksichtigung chronischer Q-Fieber-Verläufe

G. Döller

Virusantigennachweis aus dem nasopharyngealen $\mathrm{Se}$ kret zum Nachweis respiratorischer Infekte

C. Zippel

Tollwutimpfung bei Verletzungen durch Vöge R. Seuffer
Evaluation einer photometrischen Methode zur Bestimmung des Angiotensin-Converting-Enzymes

K. Mayr

Die Labordiagnose von Herpes simplex: Nachweis von Virusantigenen mit dem Enzyme-Linked-Immunsorbent-Assay und dem direkten Immunfluoreszenztest

H. Rabenau, U. Runne, B. Selb, H. W. Doerr

Erfahrungen mit einigen neueren Testsystemen in der Labordiagnostik von Chlamidia trachomatis-Infektionen

Chr. Epp, V. Barankay, H. Metz

Quantitativer Zytotoxizitätstest serologisch definierter HLA-Antigene mit Hilfe eines Bioluminiszenz-Testes J. Neumüller, G. Partsch, R. Eberl

Trübungsmeßgeräte zur Typendifferenzierung und Empfindlichkeitsprüfung von Krankheitserregern. Erfahrungen und Vergleichsuntersuchungen

Notwendigkeit von Testkombinationen zur Stellung einer relevanten Labordiagnose insbesondere von Virusinfektionen

G. Enders

Vorprogramm

Kongreß für Laboratoriumsdiagnostik

Diagnostikaforum ' 87

Alpha-1-Fetoprotein (AFP)-Bestimmung im Serum mittels Lumineszenzimmunoassay (LIA). Erste Ergebnisse im Vergleich zum Radioimmunoassay (RIA)

H. J. Schönenberger, G. Biro, H. Butz

Subtyp-spezifische Identifizierung von Influenzavirus in Zellkulturen mit FITC-markierten Antikörpern aus dem Eidotter immunisierter Hühner (lgY)

P. C. Döller, G. Döller, H.-J. Gerth

Medicometrie

Multivariate, statistische Techniken in der Klinischen Chemie und Hämatologie

H. M. J. Goldschmidt, M. N. M. Scholten

\section{INSTAND-MITTEILUNGEN}

IMLIS - International Medical Laboratory Information System

INSTAND-Terminkalender für 1986

Referenzlaboratorien und Referenzwerte

K.-G. v. Boroviczény, H. Reinauer

Über die Zuverlässigkeit der Meßergebnisse im kleinen Blutbild

A. V. Klein-Wisenberg, R. Merten, H. Reinauer, K.-G. V. Boroviczény

DIN 55350. Begriffe der Qualitätssicherung und Statistik

Konferenz „Qualitätssicherung im med. Laboratorium” H. Reinauer

20 Jahre INSTAND e. V. und 50 Jahre Hämometerprüfstelle

Nachrichten

Hormon-Ringversuche

Probenbeschaffenheit, Auswertung

G. Gries, H. Lorenz

Probenbeschaffenheit, Zielwertermittlung und andere Qualitätssicherungsprobleme bei Urinanalysen 
Krebsbehandlung: „Biologische Tumortherapie” bei kleinzelligem Bronchialkarzinom

\section{G. Bepler}

Berichte vom Abbott-Workshop "Moderne Diagnostik - Stand und Perspektive", 7. - 8. 11. 1985

OBC-Symposium in Las Vegas

Empfehlungen zur Laboratoriumsdiagnostik der Amöbiasis, Giardiasis, Kryptosporidiose und weiterer Kokzidiosen

Empfehlungen zur Laboratoriumsdiagnostik der Pneumozystose

Rolf Allner $t$

Bericht über das Diskussionsforum Virologie der Deutschen Gesellschaft für Laboratoriumsmedizin e. V.

Methodische und klinische Probleme der Röteln-Diagnostik

Kurzbericht über die "Conference internationale sur le SIDA", Paris

Ausschreibung des Hoppe-Seyler-Preises 1987

Zum Problem der Einrichtung selbständiger Abteilungen für Laboratoriumsmedizin an den Universitäten, am Beispiel Baden-Württembergs

R. Seuffer

Vergleich eines Streptokokken A- Schnelltests mit der kulturellen Untersuchung

Th. Saur

Die klinische Bedeutung des Human-Lymphozytenantigens HLA

Richtlinien für die Durchführung von Enzym-ImmunoAssays beziehungsweise Enzym-Liganden-Assays

Bericht über ein Status-Seminar zum Förderprojekt des BMFT "Verfahren der Klinischen Biochemie - Diagnostik und Infektionskrankheiten"

R. Seuffer

Medizinische Orientierungsdaten - eine Herausforderung an das Gesundheitswesen

R. Seuffer

Kommentar zu "Neopterin, ein Marker der zellulären Immunantwort"

55

56

88

118

122

170

269

271

284

\section{B. Ziegler}

Fehlermöglichkeiten des Limulus-Amöbozyten-LysatTestes bei der Endotoxinbestimmung im Serum

H. Liehr

B. Urbaschek

P. C. Fink

D. Berger

Kosten-Nutzen-Relation bei Laboruntersuchungen

B. Ziegler

\section{Grundbegriffe der Biometrie}

Qualitative Dosis-Wirkungs-Analysen

DGHM-Verfahrensrichtlinien für die mikrobiologische Dignostik

Grundriß der Parasitenkunde

Messung ionisierender Strahlung - Grundlagen und Methoden

Richtwerte für das kinderärztliche Laboratorium

Klinisch-chemische Labordiagnostik für die Praxis Lehrbuch der Pharmakologie und Toxikologie

Methods of Enzymatic Analysis, Vol. IX 
Die große Wende?

W. Hauck

Medizin am Rande der Magie?

Bericht über das Symp. „Krebs und Alternativmedizin” B. Ziegler

Bericht über die Jahrestagung der Deutschen Vereinigung zur Bekämpfung der Viruskrankheiten e. V. am 15./ 16. Nov. 85

R. Wigand

Zur Novellierung des Gesetzes über die Ausbildung d. techn. Assistenten in der Medizin

H. Reinauer

Mutterschafts-Richtlinien neu gefaßt

30 Jahre Laborarzt

W. Weimershaus

Der Arzt für Laboratoriumsmedizin

Neuordnung des einheitlichen Bewertungsmaßstabes (EBM)

Bericht über das zweite Treffen der WHO Collaborating Centres on AIDS

F. Deinhardt u. J. Abb

Kurzbericht vom 86. Annual Meeting der American Society for Microbiology

R. Seuffer

Resolutionen des Berufsverbandes Deutscher Laborärzte anläßlich des 89. Deutschen Ärztetages Hannover 1986

Thema: AIDS

Anhörung im Bundestags-Ausschuß

Jahrestagung der Deutschen Gesellschaft für Infektologie

W. Hauck

Zur Qualitätskontrolle cytogenetischer Untersuchungen und Beurteilungen

T. Schroeder-Kurth

Einhaltung der Fachgebietsgrenzen

H. Kamps

Sitzung der Arbeitsgemeinschaft der wissenschaftlich med. Fachgesellschaften (AWMF) am 19. 4.86 in Frankfurt

H. Reinauer

Standes- $u$. wettbewerbsrechtliche Probleme zwischen Laborärzten u. ärztlichen Laborgemeinschaften

R. Ratzel

Voraussetzungen für das Arbeiten mit Mikroorganismen - Anzeigepflicht, Erlaubnispflicht, Voraussetzungen

U. Lutz-Dettinger, C. Sacré, W. Steuer

20. WissenschaftI. Tagung der Deutschsprachigen Mykologischen Gesellschaft

R. Kappe

Honorarschuldner des Laborarztes bei Überweisung eines Privatpatienten durch einen anderen Arzt

R. Ratzel

Verschwindet das Labor aus dem Tätigkeitsbereich des niedergelassenen Arztes?

J. Stephan

Rechtsprobleme im Zusammenhang mit Auskunftsersuchen privater Krankenversicherer im Rahmen der Honorarliquidation

R. Ratzel

Die Medizinerschule von Kos

J. D. Kruse-Jarres

5. Wissenschaftl. Fortbildungstagung für Laboratoriumsmedizin v. 21. -28. 9. 86 in Ephesus, Türkei

A. Lapin
Empfehlungen zur Anti-HIV (Anti-LAV/HTLV III)-Diagnostik bei Blutspendern

F. Deinhard

2

101

72. Österr. Ärztekammertag fordert Verlängerung der Ausbildung der praktischen Ärzte

Ausschreibung des Förderungspreises der Österr. Ges. f. Klinische Chemie

Jahrestagung 1985 der Österr. Ges. f. Laboratoriumsmedizin

H. Lackner

Neuer Kollektivvertrag für Angestellte bei Ärzten im Bereich der Ärztekammer für Wien

5. Wissenschaftl. Fortbildungstagung für Laboratoriumsmedizin kammer nächsten Jahre

\section{AUS DEN LANDESGRUPPEN}

Treffen der Landesgruppe Hessen am 15. Januar 1986

Herbsttagung der Landesgruppe Rheinland-Pfalz u. Saarland

A. Dickgießer

Versammlung der Landesgruppe Bayern

R. Kley

Frühjahrstagung der Landesgruppe Rheinland-Pfalz u. Saarland am 19.4.86 in Kaiserslautern

Versammlung der Landesgruppe Hessen am 24. 9.86 in Bad Nauheim

\section{Sitzung der Gemeinschaft Fachärztl. Berufsverbände} am 6./7. Dez. 1985

\section{MITTEILUNGEN}

Comité Permanent der Ärzte in der EG

Vertreterversammlung d. Kassenärztl. Bundesvereinigung

89. Deutscher Ärztetag

Konzertierte Aktion konstituiert Sachverständigenrat

Sektion "Calcium-regulierende Hormone u. Knochenstoffwechsel" d. Deutschen Gesellschaft für Endokrinologie

Max-Planck-Institut für Immunbiologie in Freiburg wird erweitert

Multiple sklerose eine Autoimmunerkrankung 
Wissenschaftspreis d. Paul-Ehrlich-Ges. für Chemotherapie

Wissenschaftl. Fort- u. Weiterbildung a. d. EberhardCarls-Univ., Tübingen

Neuer Vorstand des Marburger Bundes

Verbesserte Eingruppierung von MTA

Entschließung der Vertreterversammlung der KBV zur Honorarumstrukturierung

Ergänzende Honorarvereinbarung mit den Ersatzkassen

Ausgabenentwicklung im 3. Quartal 85

Aus dem Tätigkeitsbericht ' 85 der Kassenärztl. Bundesvereinigung

75 Jahre Max-Planck-Gesellschaft

DFG verlängert Schwerpunktprogramm „Persistierende Virusinfektionen

Stahlenschutzkurse

Wissenschaftspreis d. Paul-Ehrlich-Ges. f. Chemotherapie e. V.

Bundesärztekammer zur GOÄ

Gesundheitspolitik der F. D. P.

Rötelnschutz mangelhaft

Impfung gegen Kinderlähmung

AIDS-Erkrankungen in den USA

AIDS und Impfpistolen

mta-Fachzeitschrift der Techn. Assistenten in der Medizin

Ludolf-Krehl-Preis

Stabilität von LAV/HTLV III

Europäische Vereinigung d. Fachärzte (Union Européenne de Médecine de Spécialistes = U. E. M. S.

Analytika '86

Neuer Schriftleiter der „Klinische Chemie-Mitteilungen"

Artur-Pappenheim-Preis

Helmholtz-Preis

Gerhard-Domagk-Preis

AIDS: Der heutige Stand unseres Wissens

Medizin-Geräte-Verordnung

Neuer HVM in Nord-Württemberg begrenzt die Honorare

Neuer Präsident der AWMF

Zusatzbezeichnung Sozialmedizin

„Akademie für Sozialmedizin“ mit dem Sitz in Bochum gegründet

Düsseldorfer Hygienepreis 1986

Masern-Impfung

Neuer Lepra-Impfstoff mit Hilfe der Gentechnologie

Micro-Computer' 86

dvta-Jahreshauptversammlung 1986

Gesetzlicher Nichtraucherschutz gefordert

Ärztestatistik

89. Deutscher Ärztetag zum Umweltschutz

Stichwort: Abrechnungsmanipulationen

Preis Biochemische Analytik 1986

Neuer Vorstand d. Ges. f. Mineralstoffe u. Spurenelemente

Medica '86

Curt-Adam-Preis 1987

Neue Variante des Influenza-A-Virus nachgewiesen

G. Maass

MEDICA Montreux 1986

6

6

6

16

16

16

17

17

17

18

18

18

25

25

25

26

26

26

26

26

38

39

39

40

40

40

40

58

58

58

75

75

75

76

76

76

76

76

77

88

88

89

89

90

106

106

114
H. Reineck

115

126

In 1987

126 kulose

Neuer Vorstand beim Berufsverband Deutscher Laborärzte

Neues Präsidium bei der Deutschen Gesellschaft für Laboratoriumsmedizin

14 World Congress of Anatomic and Clinical Pathology, 21. -26. Juni 87, Washington D. C.

Hepatitis-B-Impfung f. Mitarbeiter im Gesundheitswesen besonders wichtig

Impfungen in der Schwangerschaft

Gefahr der Übertragung des Hepatitis-B-Virus von infizierten Müttern auf Neugeborene

Tollwut in Europa

Laborgemeinschaft Ruhrgebiet

Wissenschaftspreis d. Paul-Ehrlich-Ges.

146

Medizingeräteverordnung

146

146

\section{AUS DEM DIN}

DEUTSCHES INSTITUT FÜR NORMUNG E.V.

Medizinische Mikrobiologie

Tuberkulosediagnostik; Mikroskopische Methoden zum

Nachweis von Mykobakterien (DIN 58943, Teil 32)

8

Sterilisation

Sterilgutversorgung; Anforderungen an die Verpakkung, Anlieferung, Lagerung $u$. Handhabung von steril gelieferten Einmalartikeln (DIN 58953, Teil 8)

Anwendungstechnik von Sterilisierbehältern (DIN 58953, Teil 9)

Gas-Sterilisatoren

Formaldehyd-Groß-Sterilisatoren

Anforderungen (DIN 58948, Teil 12)

Medizinische Mikrobiologie

Methode zur Empfindlichkeitsprüfung anaerober bakte-

rieller Krankheitserreger gegen Chemotherapeutika;

Agardilutionstest (6)

DIN 58944 T 102.86

DIN 58944 T 202.86

BbI 1 zu DIN 58944 T 202.86

Transfusionseinrichtungen für med. Zwecke

Blutentnahmegerät

(DIN 58372)

78

Sterilisation

Heißluft-Sterilisatoren; Bio-Indikatoren zur Prüfung der

Wirksamkeit (DIN 58947, Teil 4)

Sterilisation

Dampf-Sterilisatoren; Begriffe (DIN 58946, Teil 1)

Sterilisation

Dampf-Sterilisatoren; Bio-Indikatoren; Begriffe, Anforderungen, Prüfung (DIN 58946, Teil 4)

Sterilisation

Gas-Sterilisatoren; Ethylenoxid-Groß-Sterilisatoren: Anforderungen (DIN 58948, Teil 2)

Sterilisation

Gas-Sterilisatoren; Prüfung auf Wirksamkeit von Ethy-

lenoxid-Gas-Sterilisatoren (DIN 58948, Teil 3) 
Sterilisation

Gas-Sterilisatoren; Betrieb von Ethylenoxid-Gas-Sterilisatoren (DIN 58948, Teil 6)

Sterilisation

Gas-Sterilisatoren; Bio-Indikatoren zur Prüfung auf Wirksamkeit von Ethylenoxid-Gas-Sterilisatoren für den industriellen Bereich (DIN 58948, Teil 8)

Sterilisation

Gas-Sterilisatoren; Bio-Indikatoren zur Prüfung auf Wirksamkeit von Ethylenoxid-Gas--Sterilisatoren für den Krankenhausbereich (DIN 58948, Teil 4)

Methoden zur Empfindlichkeitsprüfung von bakteriellen Krankheitserregern (außer Mykobakterien) gegen Chemotherapeutika; Bewertungsstufen der minimalen Hemmkonzentration; Liste der durchschnittlichen Tagesdosierung (DIN 58940, Teil 4, Beiblatt 2)

Gerinnungsanalytik; Referenzplasma; Begriffe, Anforderungen, Herstellung (DIN 58939)

Sterilisation

Sterilgutversorgung; Gekrepptes u. glattes Sterilisationspapier zum Einschlagen von Sterilisiergut; Anforderungen, Prüfung (DIN 58953, Teil 5)

Sterilisation

Sterilgutversorgung; Sterilisationspapier für Beutel u. Schlauchverpackungen; Prüfung (DIN 58953, Teil 6)

Infusion

Infusionsgeräte u. Zubehör; Infusionsgeräte f. Schwerkraftinfusionen; Benennungen, Anforderungen, Prüfung (DIN 58362, Teil 1)

Infusion

Infusionsgeräte $u$. Zubehör; Infusionsgeräte zur Verwendung in Druckinfusionsapparaten; Benennungen, Anforderungen, Prüfung (DIN 58362, Teil 2)

Med. Mikrobiologie

Tuberkulosediagnostik; Modifiziertes Löwenstein-Jensen-Kulturmedium zur Anzüchtung von Tuberkulosebakterien (DIN 58943, Teil 7)

Desinfektion

Dampf-Desinfektionsapparate; Begriffe (DIN 58949, Teil

Arbeitsausschuß Immunologie, Serodiagnostik von Infektionskrankheiten

Med. Mikrobiologie

Kulturmedien für die Bakteriologie; Überlebensfähigkeit von Mikroorganismen in gebrauchsfertigen Transportsystemen (DIN 58942, Teil 4, Beiblatt 1)

Tuberkulosediagnostik

Kulturelle Methoden zur Isolierung von Mykobakterien (DIN 58943, Teil 3)

\section{LESERZUSCHRIFTEN}

Beschäftigung Schwangerer in medizinischen Laboratorien

R. Dahn u. U. Dickgießer

PKV verunsichert Patienten durch vorsätzliche Begriffsfälschungen

R. Seuffer

Beschäftigung Schwangerer in medizinischen Laboratorien

R. Seuffer

J. Stephan

Klarheit in der Laboratoriumsmedizin

R. Seuffer

Der neue Mutterpaß

R. Seuffer

Fluoreszenzfärbung von Pilzen in Originalmaterial

R. Seuffer

93

93

96

96

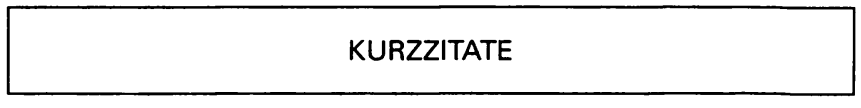

BDL 32, 40, 96, 107, 108, 119, 122

BDL 126, 128, 146

\section{BUCHBESPRECHUNGEN}

Das Recht der Heilhilfsberufe, Hebammen u. Heilpraktiker

A. Theobald, H. Erdle

Method of Enzymatic Analysis

H. U. Bergmeyer

Medizinisch-literarischer Almanach auf das Jahr 1986

Hrsg. W. Theopold

AIDS

Hrsg. G. K. Steigleder

Automation der Zytologischen Diagnostik

Hrsg. Deutsche Forschungs- $u$. Versuchsanstalt f. Luft- $u$. Raumfahrt e. $V$

Die Sicherheit medizinisch-technischer Geräte

Die Si

Sicherheitsvorschriften f. med.-techn. Geräte

M. Nöthlichs, H. P. Weber

Effizienz und Effektivität med. Diagnostik

Hrsg. H. R. Vogel

Sicherheitsvorschriften f. med.-technische Geräte M. Nöthlichs

Hrsg. F. Gschnait, K. Wolff

AIDS

F. Rühmann

An den Grenzen der Schulmedizin - eine Analyse umstrittener Methoden

Hrsg. I. Oepen

Viruserkrankungen - Leitfaden für Kinderärzte, Allgemeinärzte u. Internisten

F.W. Wedemeyer

AIDS-Forschung

62

Medizinstudium u. Weiterbildung in den USA

W. Esch

JURAMED - Recht des niedergelassenen Arztes

W. M. Nentwig

Immunologische Abwehr und Krebs

J. Milleck

Königsteiner Chromatographie-Tage

Das Recht der Heilhilfsberufe, Hebammen und Heilpraktiker

A. Theobald, H. Erdle

Neue tumorassoziierte Antigene

Hrsg. H. Greten, R. Klapdor

Handlexikon des Kassenarzt- u. Kassenzahnarztrechts u. d. angrenzenden Rechtsgebiete

R. Liebold

Endokrinologie in der Schwangerschaft

Hrsg. M. Breckwoldt

Klinische Immunpathologie

G. R. F. Krueger

HTLV-III-Infektionen - Problem für die zahnärztliche Praxis?

Hrsg. G. Knolle

Wörterbuch der Medizin-Zahnheilkunde und Grenzgebiet 
exikon des Arztrechts

1.-J. Rieger

ostenstruktur bei Ärzten, Zahnärzten, Tierärzten 1983 irsg. Stat. Bundesamt, Wiesbaden

Biochemical and Clinical Aspects of Pteridines

Hrsg. H. Wachter, H. Ch. Curtius, W. Pfleiderer

mmunoassay Technology

Hrsg. S. B. Pal

nfektionen bei Schwangeren und ihren Neugeborenen W. Ehrengut

Grundriß der Parasitenkunde

H. Mehlhorn, G. Piekarski

Kompendium der veterinärmedizinischen Bakteriologie J. Nicolet

Ärztliches Berufsrecht

Ausbildung - Weiterbildung - Berufsausbildung H. Narr

Das Recht der Heilhilfsberufe, Hebammen u. Heilprakti-

A. Theobald, H. Erdle

Pathogenese $\mathrm{U}$. Klinik der Harnsteine XI

Hrsg. G. Gasser, W. Vahlensieck

Farbatlas mikroskopischer Harnanalytik

M. H. Haber

Monoklonale Antikörper - Herstellung u. Charakterisierung

J. H. Peters, H. Baumgarten, M. Schulze

Die Bestimmung der Spurenelemente und ihre klinische Bedeutung

K. Dörner

JURAMED - Recht des niedergelassenen Arztes W. M. Nentwig

Ion- and Molecule-Selective Electrodes in Biological Systems

J. Havas

Präparationsmethodik in der Elektronenmikroskopie D. G. Robinson, U. Ehlers, R. Herken, B. Herrmann, F Mayer, F.-W. Schürmann

Krebs und Alternativmedizin

Hrsg. W. F. Jungi, H. J. Senn

Farbatlas der Mikrobiologie - Anleitung zur Diagnose

R. J. Olds

Signatur
EINGEGANGENE BÜCHER

BDL $9,14,42,54,72,74,79,86,99,112,116,122,147$

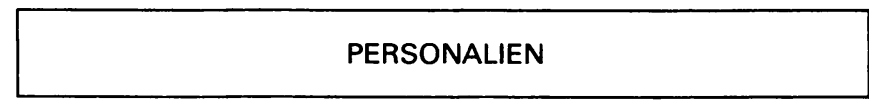

BDL $6,18,28,40,58,59,77,90,106,116,122,147$

Otto Fenner - 65 Jahre $\quad$ BDL 58

Wolfgang Albath - 40 Jahre Laborarzt $\quad$ BDL 59

$\begin{array}{ll}\text { Johanna Schullert } & \text { BDL } 90\end{array}$

BDL $10,19,24,34,45,64,84,99,110,112,120,132,147$

TERMINKALENDER

BDL $12,24,36,48,64,84,100,112,120,132,148$ 


\title{
Häufigkeit und klinischer Verlauf jodinduzierter Hyperthyreosen
}

\author{
N. Pocker, D. Jüngst
}

Med. Klinik 2, Klinikum Großhadern der Universität München (Direktor Prof. Dr. med. G. Paumgartner)

\section{Zusammenfassung:}

Bei 27 von 93 Patienten mit Hyperthyreose wurde eine Jodkontamination anamnestisch nachgewiesen. In 25 Fällen war eine Kontrastmittelapplikation vorangegangen, ein Patient stand unter einer Therapie mit Amiodaron und eine Patientin wurde mit Polyvidonjod behandelt. Der überwiegende Anteil, 18 von 27 Patienten (67\%), zeigte einen milden klinischen Verlauf. Sieben Patienten entwickelten ausgeprägte Hyperthyreosesymptome, und bei 2 Patienten kam es zu einer thyreotoxischen Krise.

Bei den Fällen mit geringer Symptomatik, die keine oder niedrig dosierte Thyreostatika erhielten, wurde 3-5 Wochen nach Normalisierung des Gesamtjods im Serum eine euthyreote Schilddrüsenfunktion und Hormonsekretion festgestellt. Das Absetzen der thyreostatischen Therapie nach diesem Zeitraum führte in keinem Fall zu einem Hyperthyreoserezidiv. Neun Patienten nahmen aufgrund stärkerer Hyperthyreosesymptomatik höhere Dosen von Thyreostatika ein. Bei 6 dieser Patienten wurde in der Folge eine Radiojodtherapie und bei 1 Patienten eine subtotale Strumektomie durchgeführt.

Während die Diagnose der Jodkontamination bei Hyperthyreose bereits zuverlässig durch die Anamnese gestellt werden kann, gibt die Verlaufskontrolle des Gesamtjods im Serum bei therapiebedürftigen Patienten Anhaltspunkte für die erforderliche Dauer einer thyreostatischen Behandlung.

Schlüsse/wörter:

Hyperthyreose - Gesamtjod im Serum - Verlauf - Häufigkeit - Diagnostik

\section{Summary:}

lodine induced hyperthyroidism was diagnosed in 27 of 93 patients (29\%) with elevated thyroid hormones. From these 25 had previous radiographic examinations with iodine containing contrast media, 1 patient was treated with amiodarone and another with polyvidoniodine. Eighteen of these 27 patients (67\%) revealed only mild clinical symptoms. Seven patients showed moderate signs of hyperthyroidism and in 2 thyroid storm developed. Among the cases displaying benign thyrotoxic symptoms with no or low dose antithyroid treatment follow up studies demonstrated a normalization of thyroid function and hormone levels 3-5 weeks after the elimination of excess serum iodine. By this time antithyroid medication has been discontinued and no relapse occurred. From the 9 patients with more severe symptoms who initially obtained higher doses of antithyroid drugs 6 were subsequently submitted to radiotherapy with ${ }^{131}$ iodine and 1 to subtotal thyroidectomy.

Although iodine induced hyperthyroidism has been diagnosed in all 27 patients by history, follow up studies observing total serum iodine concentrations are useful to determine the duration of specific therapy in patients which require antithyroid drugs.

\section{Keywords:}

Hyperthyroidism - Total serum iodine - Follow up - Prevalence - Diagnosis

\section{Einleitung}

Bereits Coindet, der vor 165 Jahren erstmals die Wirksamkeit einer Jodtherapie bei Jodmangelstrumen nachwies, erkannte einen Zusammenhang zwischen der Verabreichung höherer Joddosen und dem Auftreten von Hyperthyreosesymptomen bei einem Teil seiner Patienten $(1,2)$. Auch nach Erhöhung des Jodgehaltes in der Ernährung in verschiedenen Strumaendemiegebieten beobachtete man einen passageren Anstieg der Hyperthyreoseinzidenz bei den betroffenen Bevölkerungsgruppen (3-5).
Chronischer Jodmangel kann zu morphologischen Veränderungen in der Schilddrüse führen und begünstigt das Auftreten von fokalen und disseminierten Autonomien $(6-8)$. Insbesondere in diesen Fällen kann durch meist iatrogene Jodzufuhr eine hyperthyreote Stoffwechsellage entstehen. Es war Ziel der vorliegenden Studie, die Häufigkeit der jodinduzierten Hyperthyreose und deren klinische Verlaufsform zu untersuchen. Die Gesamtjodbestimmung wurde dabei sowohl bei der Diagnostik als auch zur Verlaufsbeurteilung mit herangezogen. 


\section{Material und Methoden}

Das untersuchte Kollektiv umfaßte 93 Patienten mit hyperthyreoter Stoffwechsellage, die sich in ambulanter bzw. stationärer Behandlung der Medizinischen Klinik 1-III des Klinikums Großhadern befanden. Die Diagnose stützte sich neben der klinischen Symptomatik auf die Konzentration der Schilddrüsenhormone und auf eine fehlende TSH-Stimulation nach $200 \mu \mathrm{g}$ TRH intravenös. Alle Fälle mit kontrastmittelinduzierter Schilddrüsenfunktionsstörung wiesen Hyperthyreosesymptome auf, jedoch waren diese unterschiedlich stark ausgeprägt. Die beiden Patienten unter einer Behandlung mit Amiodaron (Cordarone ${ }^{\circledR}$ ) bzw. Polyvidonjod zeigten nur eine geringe Hyperthyreosesymptomatik.

Das Thyroxin im Serum wurde nach einer enzymimmunologischen Methode bestimmt ( $\mathrm{T}_{4}$-EIA, SYVA Comp., Palo Alto, USA). Der Referenzbereich wird zwischen 4,0 und $10,5 \mu \mathrm{g} / \mathrm{dl}$ angegeben. Trijodthyronin- und TSH-Bestimmungen erfolgten radioimmunologisch mit kommerziellen Test-Kits ( $T_{3}-R \mid A$, Micromedic Systems, Inc. Rohm und Haas Comp., PA, USA, TSH-RIA, Firma Henning, Berlin). Der Referenzbereich für $\mathrm{T}_{3}$ liegt zwischen 0,9 und $2,3 \mathrm{ng} / \mathrm{ml}$, für das basale TSH zwischen 0,8 und $3,2 \mu \mathrm{U} / \mathrm{ml}$ und für Delta-TSH zwischen 1,5 und 20,0 $\mu \mathrm{U} /$ $\mathrm{ml}$. Das Gesamtjod im Serum wurde mit dem Technicon Auto Analyzer gemessen (Instruction Manual No. PB/ D-1 Technicon Instruments Corporation, Ardsley, New York).

Der freie Jodanteil im Serum errechnete sich aus der Differenz zwischen Gesamtjod und Thyroxinjod, wobei das Thyroxinjod aus der Thyroxinkonzentration in $\mu \mathrm{g} /$ dl $\times 0,65$ ermittelt wurde. Um den Einfluß physiologischer Einflüsse im Jodstoffwechsel oder sich addierende Meßungenauigkeiten bei $\mathrm{T}_{4}$ - und Gesamtjodbestimmung auszuschließen, war für die laborchemische Diagnose einer Jodkontamination mindestens eine Konzentration von $5,0 \mu \mathrm{g} / \mathrm{dl}$ freies Jod erforderlich. Bei 332 Patienten ohne anamnestische Jodapplikation lagen die freien Jodwerte unter dieser Grenze mit einer mittleren Konzentration von 1,3 $\mu \mathrm{g} / \mathrm{dl}$ und einer Standardabweichung von $0,7 \mu \mathrm{g} / \mathrm{dl}$.

\section{Ergebnisse}

Aufgrund der eingehenden Anamnese konnte bei 27 von 93 Patienten mit Hyperthyreose, entsprechend 29\%, eine vorangegangene Jodapplikation festgestellt werden. Während 6 dieser Patienten bereits normale Jodkonzentrationen im Serum aufwiesen, war bei den übrigen 21 Patienten die freie Jodkonzentration im Serum über $5,0 \mu \mathrm{g} / \mathrm{dl}$ erhöht. Ganz überwiegend handelte es sich bei der Jodapplikation um Kontrastmitteluntersuchungen, dagegen waren andere Jodquellen nur von untergeordneter Bedeutung.

Bei den 25 Patienten mit Kontrastmittelexposition standen Untersuchungen der Nieren und Galle mit 17 Fällen im Vordergrund, 4mal war eine Herzkatheteruntersuchung vorgenommen worden, 3mal eine Angiographie und $1 \mathrm{mal}$ wurde im Rahmen einer Computertomographie des Abdomens Kontrastmittel appliziert. Bei einem $\mathrm{Pa}$ tienten hatte eine Therapie mit dem Antiarrhythmikum Amiodaron (Cordarone ${ }^{\circledR}$ ) die Jodkontamination bewirkt, und eine Patientin bekam längerfristig Polyvidonjod verabreicht.

In Abb. 1 sind die Werte von Gesamtjod und freiem Jod für die Hyperthyreosen mit Jodexposition sowie für die nicht kontaminierten Fälle aufgetragen. Jene 6 Patienten, bei denen sich die Gesamtjodspiegel im Serum zum Zeitpunkt der Diagnosestellung bzw. ihrer Erstuntersuchung in der Klinik bereits wieder normalisiert hatten, erscheinen

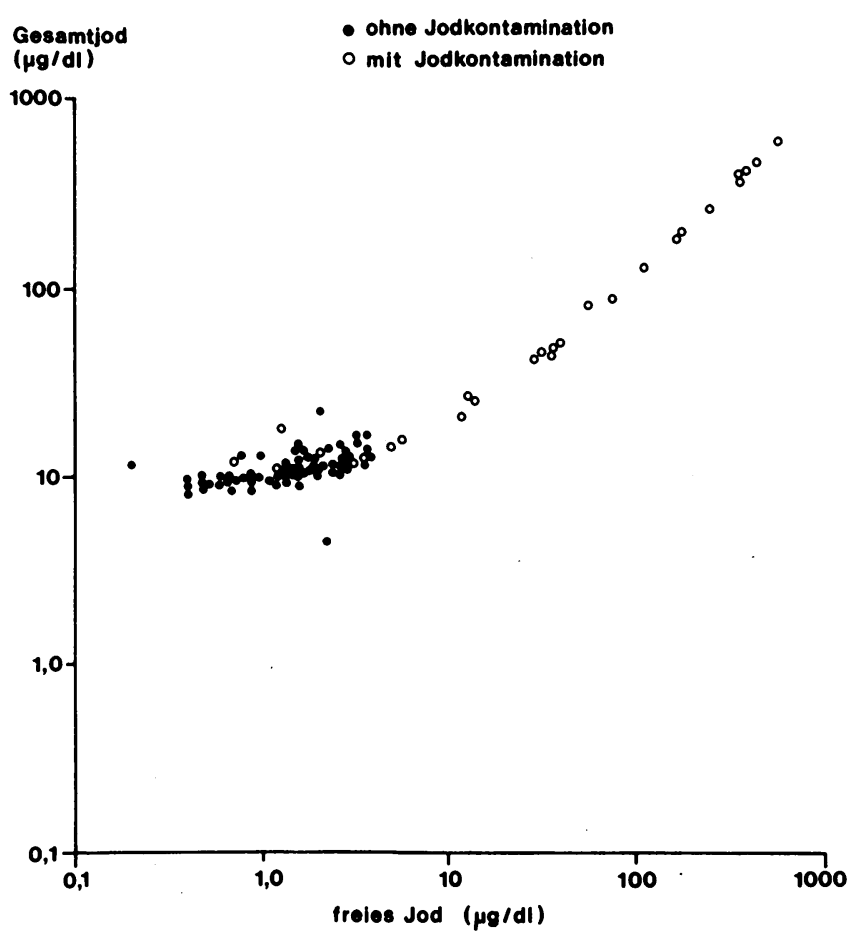

Abb. 1: Relation von Gesamtjod und freiem Jod zum Zeitpunkt der Diagnosestellung bei 27 Patienten mit und 66 ohne jodinduzierte Hyperthyreose
- ohne Jodkontamination o mit Jodkontamination

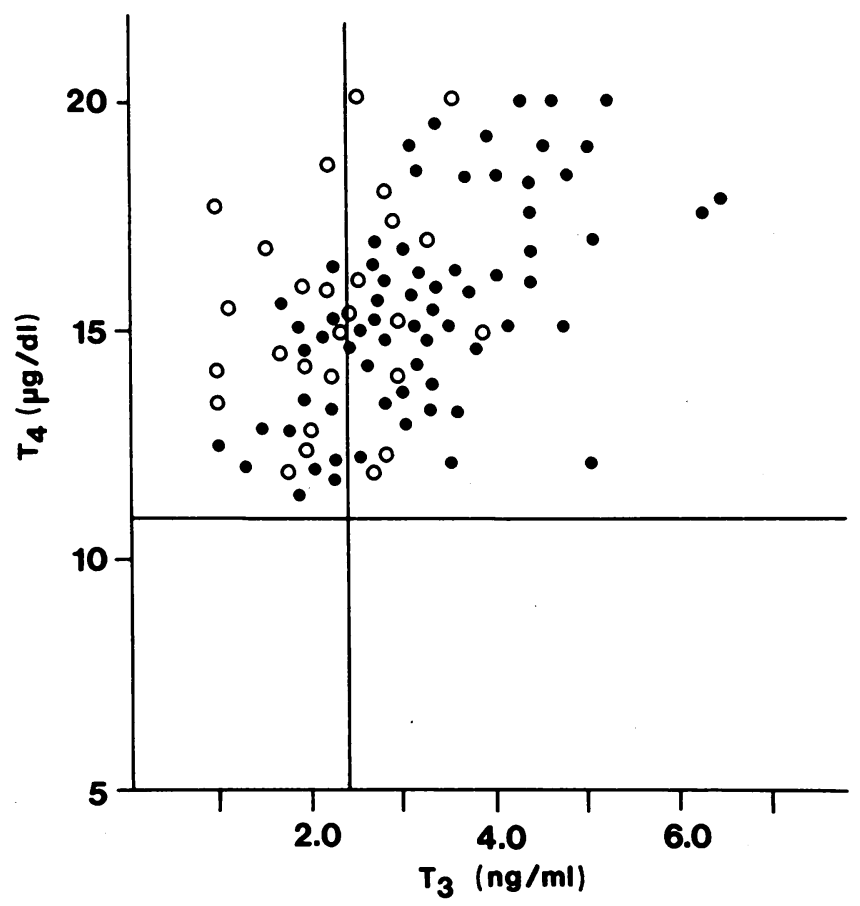

Abb.2: $T_{3} / T_{4}-$ Werte von 93 hyperthyreoten Patienten mit 27 jodkontaminierten und 66 nicht jodkontaminierten Fällen 
in der Darstellung im Bereich der Hyperthyreosen ohne Jodanamnese. Bei einer Patientin des nicht kontaminierten Kollektivs, mit sehr niedrigen Jodwerten, bestand eine $\mathrm{T}_{3}$ - Hyperthyreose. Das Lebensalter der 27 Patienten mit jodinduzierter Hyperthyreose lag zwischen 43 und 79 Jahren (Median 64 Jahre) und unterschied sich nicht signifikant vom Alter der 66 Patienten ohne Jodkontamination (Bereich 19-84 Jahre, Median 60 Jahre).

Bei allen 93 Personen mit nachgewiesener Schilddrüsenüberfunktion fand sich eine erhöhte Thyroxinkonzentration, dagegen lagen die $T_{3}$-Werte bei $23,4 \%$ der nicht kontaminierten und bei $51,7 \%$ der Patienten mit jodinduzierter Hyperthyreose im Referenzbereich. In Abb. 2 sind die Einzelwerte von $T_{4}$ und $T_{3}$ dargestellt. Während keine signifikanten Unterschiede bezüglich der Thyroxinkonzentrationen bestehen, ergeben die $\mathrm{T}_{3}$-Bestimmungen bei den 27 hyperthyreoten Patienten mit Jodkontamination signifikant $(p<, 0,01)$ niedrigere Werte $(\bar{x}=2,03 \mathrm{ng} / \mathrm{ml})$ als bei den 66 Patienten mit hyperthyreoter Stoffwechsellage ohne Jodexposition $(\bar{x}=3,15 \mathrm{ng} /$ $\mathrm{ml}$ ).

Bei den Patienten mit jodinduzierter Hyperthyreose wurde in $36 \%$ eine Struma diffusa $1-111$, in $28 \%$ eine Struma diffusa partim. nodosa I-III, in $16 \%$ eine Struma nodosa I-III und in $20 \%$ ein autonomes Adenom der Schilddrüse diagnostiziert. In der Gruppe ohne Jodkontamination lag ebenfalls bei $36 \%$ eine Struma diffusa I-III vor, bei $19 \%$ eine Struma diffusa partim nodosa I-III, bei $25 \%$ eine Struma nodosa I-III und bei $20 \%$ ein autonomes Adenom.

Um den klinischen Verlauf der jodinduzierten Hyperthyreosen beurteilen zu können, unterzogen sich die betroffenen Patienten über einen Zeitraum von 2-4 Monaten regelmäßigen Nachuntersuchungen. Neben den Kontrollen der Schilddrüsenhormone wurde jeweils auch das Gesamtjod im Serum gemessen. An einigen ausgewählten Fällen sollen zunächst typische Verlaufsformen dargestellt werden.

Bei einem 76jährigen Patienten wurde ein Infusionscholecystogramm unter dem Verdacht einer Cholangiolithi- asis durchgeführt. Etwa 2 Wochen nach Kontrastmittelapplikation kam es zu einem allmählichen Anstieg der $\mathrm{T}_{4}$ und auch der $\mathrm{T}_{3}$-Konzentrationen (Abb. 3). Das Gesamtjod im Serum erreichte Maximalwerte bis $400 \mu \mathrm{g} / \mathrm{dl}$ und normalisierte sich im Laufe von 4-5 Wochen. Wegen klinischer Hyperthyreosezeichen erhielt der Patient über 5 Wochen $40 \mathrm{mg}$ Favistan ${ }^{\circledR}$ täglich, worunter eine Euthyreose erzielt wurde. Nach Absetzen dieser Medikation blieben die Schilddrüsenhormonwerte im Referenzbereich.

Da später der szintigraphische Nachweis eines dekompensierten autonomen Adenoms der Schilddrüse erbracht werden konnte, wurde die Indikation zur Radiojodtherapie gestellt.

Bei einer 68jährigen Patientin mit vorbestehender Struma nodosa II stiegen die Schilddrüsenhormone im Anschluß an ein Urogramm auf hyperthyreote Werte an. Als deren Folge kam es zu einer zunehmenden Herzinsuffizienz. Unter thyreostatischer Behandlung über 3 Wochen ließ sich die Stoffwechsellage normalisieren. Bereits innerhalb weniger Tage (Abb.4) waren die vorher sehr hohen Jodwerte im Serum in den Normbereich zurückgekehrt. Nach Absetzen der thyreostatischen Therapie blieb die Patientin euthyreot.

Bei einer 63jährigen Patientin, die wegen eines Abszesses über mehrere Monate lokal mit Polyvidonjod behandelt wurde, stieg die Jodkonzentration im Serum auf Werte bis zu $400 \mu \mathrm{g} / \mathrm{dl}$. Nach etwa einem Monat beobachtete man eine über die Norm erhöhte $\mathrm{T}_{4}$-Konzentration, ohne daß die Patientin eine deutliche klinische Hyperthyreosesymptomatik entwickelte. Nach Absetzen der Polyvidonjodtherapie normalisierten sich die Jodspiegel im Serum, und mit einer Verzögerung von etwa 4 Wochen gingen auch die Thyroxinwerte in den Referenzbereich zurück (Abb.5). Eine spezifische Therapie war nicht erforderlich.

Ein 54jähriger Patient wurde wegen einer tachykarden Rhythmusstörung mit Amiodaron (Cardarone ${ }^{\circledR}, 400 \mathrm{mg}$ tgl.) behandelt. Aufgrund einer toxischen Leberschädigung mußte diese Therapie jedoch abgebrochen werden.

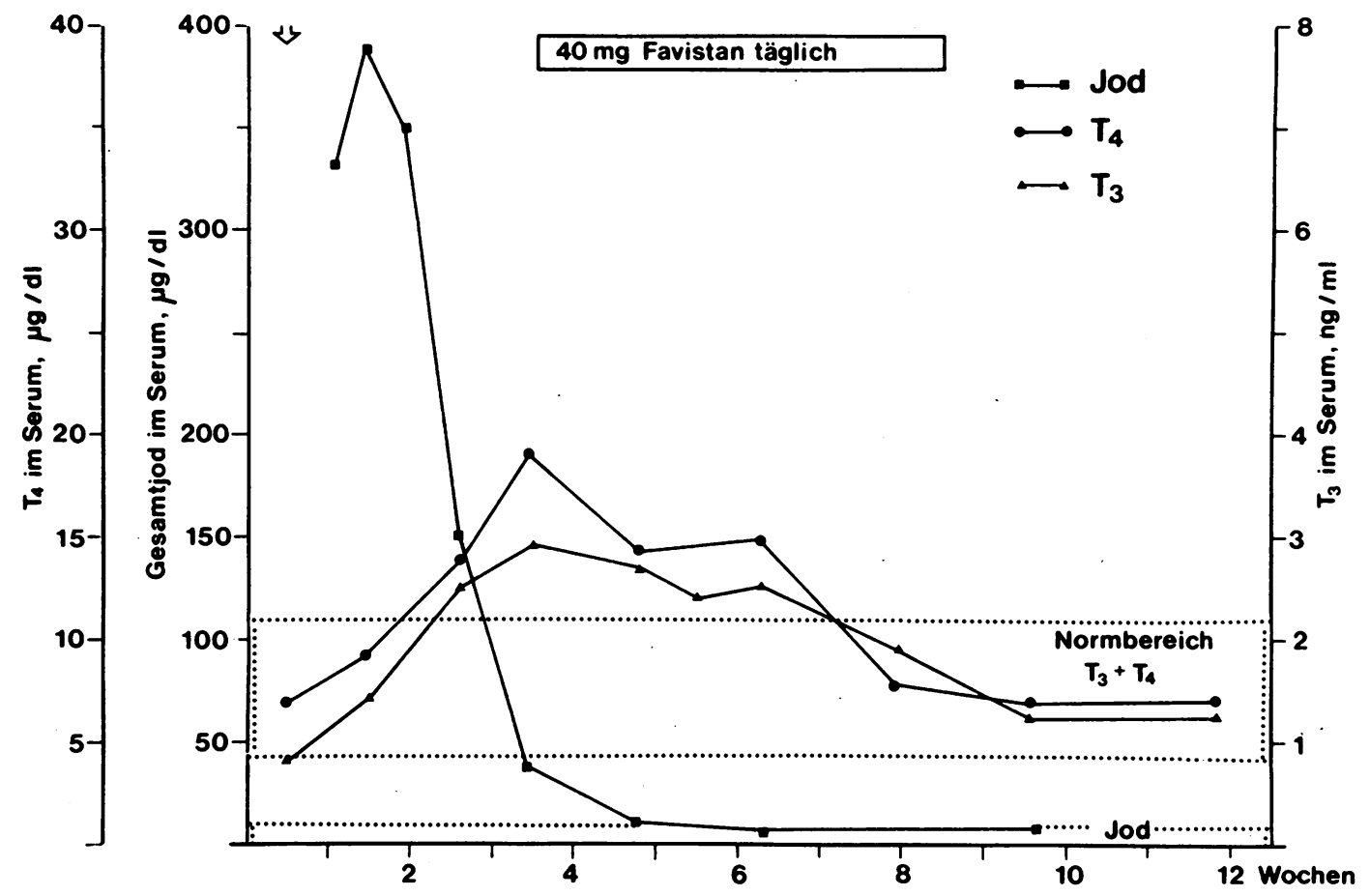

Abb. 3:

Hyperthyreoseverlauf eines 76jährigen Patienten mit dekompensiertem autonomem Adenom nach Jodkontamination durch ein Infusionscholecystogramm 
Während die $T_{3}$-Konzentrationen ständig im Referenzbereich blieben, erreichten die Thyroxinspiegel bei dem $\mathrm{Pa}$ tienten sehr hohe Werte. Eine klinische Symptomatik war nur gering ausgeprägt, doch war die Beurteilung wegen der Amiodaronbehandlung erschwert. Nach Elimination des Amiodarons, welche an den absinkenden Jodkonzentrationen zu erkennen war, normalisierten sich auch die erhöhten $\mathrm{T}_{4}$-Werte (Abb.6).

Der überwiegende Anteil, 18 von 27 Patienten mit jodinduzierter Hyperthyreose (67\%), zeigte einen milden kli- nischen Verlauf, der in 6 Fällen keine spezifische Behandlung erforderte, während bei 12 Patienten eine niedrig dosierte Therapie (10-20 mg Favistan ${ }^{\circledR}$ tgl.) indiziert war. Nach Elimination des Jods kam es mit einer zeitlichen Verzögerung von 3-5 Wochen auch zu einer Normalisierung der erhöhten Schilddrüsenhormonwerte. Bei $9 \mathrm{~Pa}-$ tienten bestanden ausgeprägtere Hyperthyreosesymptome, welche zunächst mit höheren Dosen (40-60 mg Favistan ${ }^{\circledR} \operatorname{tgl}$.) von Thyreostatika behandelt wurden. Gründe wie der nachträgliche szintigraphische Nachweis eines autonomen Adenoms, das Auftreten von leuko-
Abb. 4:

Hyperthyreoseverlauf einer 68jährigen Strumapatientin nach Jodkontamination durch ein Ausscheidungsurogramm
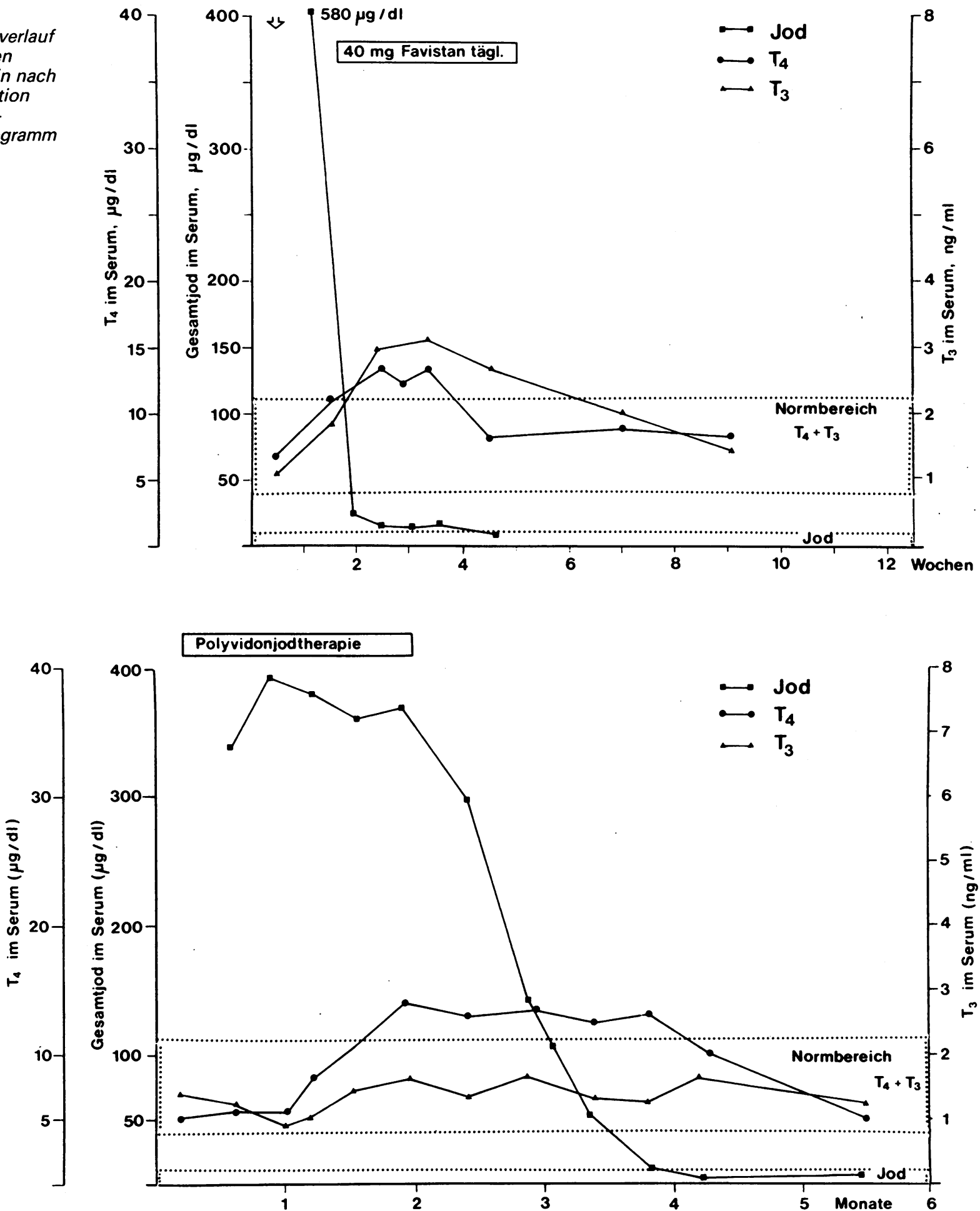

Abb. 5: Verlaufsbeobachtung einer 63jährigen Patientin ohne klinische Hyperthyreosesymptomatik bei längerfristiger lokaler Polyvidonjodapplikation 
thrombocytopenischen Reaktionen bzw. die Persistenz der Hyperthyreosesymptomatik zwangen nachfolgend zu ablativen Maßnahmen. Bei 6 Patienten wurde eine Radiojodtherapie und bei 1 Patienten eine subtotale Strumektomie durchgeführt. Zwei Patienten entwickelten nach Jodapplikation ein schweres Krankheitsbild im Sinne einer thyreotoxischen Krise, die intensivmedizinisch behandelt werden mußte.

\section{Diskussion}

Insbesondere bei Strumaträgern in Endemiegebieten steigt das Autonomierisiko mit längerem Krankheitsverlauf deutlich an. Demzufolge erhöht sich die Möglichkeit, durch Jodkontamination eine hyperthyreote Stoffwechsellage zu induzieren (9). In der vorliegenden Studie konnte bei 27 von 93 Patienten (29\%) mit Hyperthyreose eine Jodkontamination nachgewiesen werden, die ganz überwiegend durch vorangegangene Untersuchungen mit Röntgenkontrastmitteln bedingt war. Ähnliche Untersuchungen ergaben in $21,3 \%$ der hyperthyreoten Patienten eine Jodkontamination (10). Andere Autoren unterschieden zusätzlich zwischen immunogener Hyperthyreose (Morbus Basedow) und nicht immunogener Hyperthyreose (disseminierte und lokalisierte Autonomie) (11). Dabei fanden sie in $16 \%$ bei immunogener, aber in $82 \%$ bei nicht immunogener Schilddrüsenüberfunktion Jod als auslösenden Faktor.

Eine eindeutige Trennung in immunogene und nicht immunogene ist in unserer Untersuchung nicht in allen Fällen möglich gewesen, doch zeigen die szintigraphischen Befunde keine Unterschiede zwischen der kontaminierten und der nicht kontaminierten Gruppe.

Auch der Anteil der autonomen Adenome war in beiden Gruppen gleich. Ein sehr hoher Anteil jodinduzierter $\mathrm{Hy}$ perthyreosen wurde im Endemiegebiet von Marburg beobachtet (12). Danach war in annähernd $80 \%$ der neu aufgetretenen Hyperthyreosen eine Jodkontamination ursächlich an der Dekompensation bereits bestehender fokaler oder disseminierter Autonomien beteiligt.

Obwohl daraus die Bedeutung jodinduzierter Veränderungen der Schilddrüsenfunktion insbesondere in Jodmangelgebieten offensichtlich wird, gibt es keine routinemäßig anwendbare Methodik, um die Wahrscheinlichkeit einer Hyperthyreoseentstehung nach Jodapplikation abzuschätzen $(9,13)$. So fallen bei euthyreoten Personen mit einer kompensierten Schilddrüsenautonomie nicht nur die $T_{3} / T_{4}$-Bestimmung, sondern in fast $80 \%$ auch der TRH-Test normal aus (14). Eine Beurteilung des Risikos soll allerdings durch Quantifizierung des autonomen $\mathrm{Ge}$ webes unter Verwendung der inversen Korrelation des $99 \mathrm{~m}$ Tc-Thyroid-Uptake mit dem freien Thyroxin-Äquivalent möglich sein (15).

Neben der Menge autonomen Gewebes, wobei die kritische Grenze mit etwa $5 \mathrm{ml}$ angegeben wird, spielt die biochemische Beschaffenheit und Bioverfügbarkeit der applizierten jodhaltigen Substanz für die mögliche Induktion einer Hyperthyreose eine entscheidende Rolle. So ist das Hyperthyreoserisiko wesentlich geringer nach Verabreichung auch großer Mengen wasserlöslicher Kontrastmittel mit schwacher Proteinbindung und folglich rascher renaler Elimination als nach Verwendung von fettlöslichen Mitteln mit Rückresorption über den enterohepatischen Kreislauf, wie z. B. nach intravenösen und besonders oralen Cholecystographien (16-18). Entsprechend blieb bei den Verlaufsbeobachtungen das Gesamtjod im Serum nach Angiographie oder Urographie oft nur wenige Tage bis eine Woche erhöht. In 6 Fällen lag die Jodkonzentration bei Diagnosestellung oder Erstuntersuchung in der Klinik wieder im Normbereich, obwohl nach Anamnese die hyperthyreote Stoffwechsellage eindeutig nach einer Kontrastmittelapplikation aufgetreten war. Eine normale Konzentration von Gesamtjod und freiem Jod schließt daher eine jodinduzierte Hyperthyreose keineswegs aus. Hier kann nur durch eine sorgfältige Anamnese der Nachweis dieser Hyperthyreoseform geführt werden.

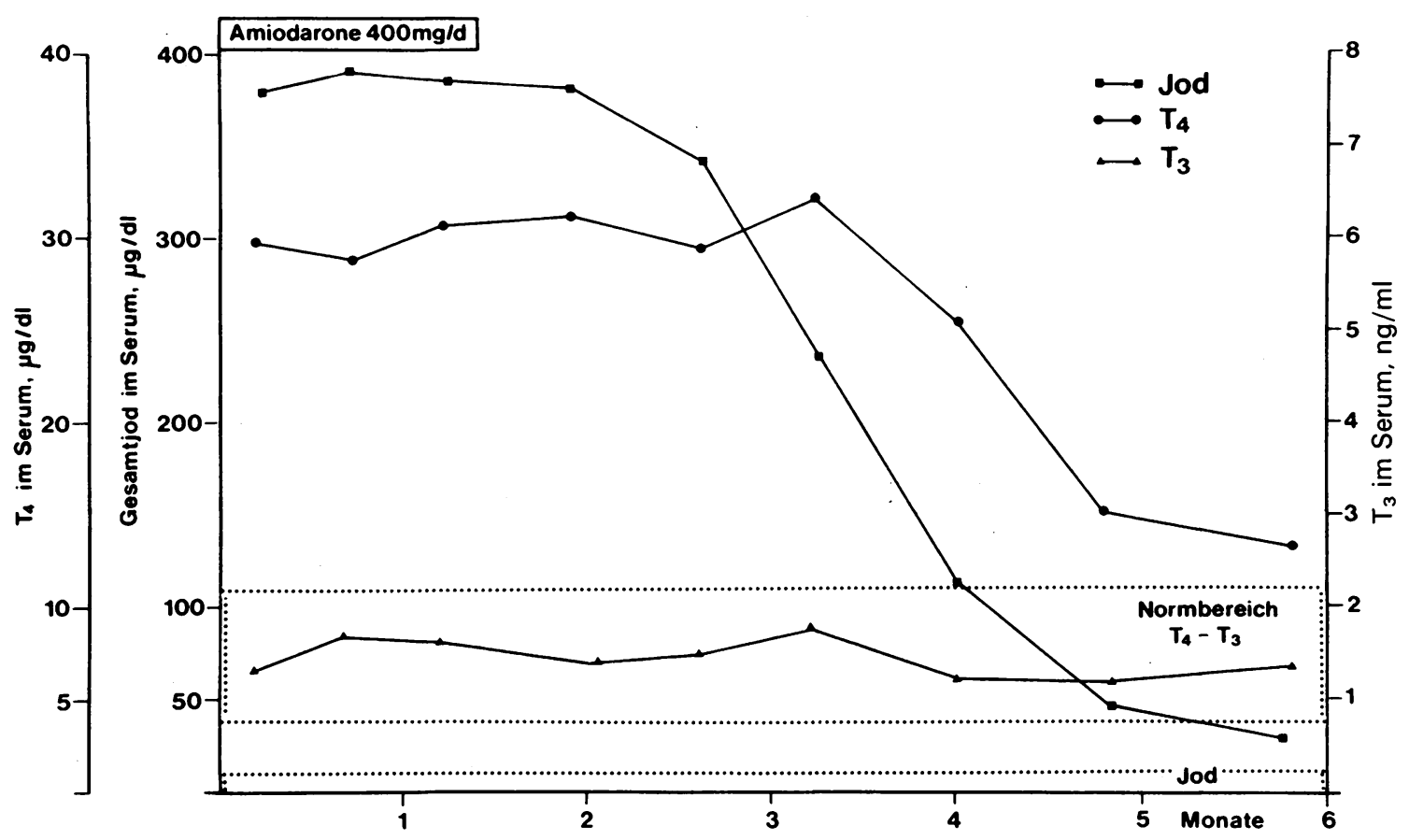

Abb. 6: Verlaufsbeobachtung eines 54jährigen Patienten mit nur geringer klinischer Hyperthyreosesymptomatik bei chronischer Jodkontamination durch Amiodaron 
In Übereinstimmung mit anderen Autoren fanden sich bei den jodinduzierten Hyperthyreosen signifikant niedrigere $\mathrm{T}_{3}$-Spiegel als bei jenen ohne Jodkontamination (19, 20). Dennoch wird die durch chronische Jodzufuhr verursachte Verminderung der $T_{4}-z u T_{3}$-Konversion für die akute Jodexposition bislang kontrovers diskutiert $(10,21$, $22,23)$. Die Vermutung, daß mit zunehmendem Alter der Patienten bei der Abklärung anderer Erkrankungen die Wahrscheinlichkeit einer Jodkontamination und somit das Hyperthyreoserisiko steigt, konnte nicht eindeutig bestätigt werden (12). Zwar war der jüngste Patient der jodkontaminierten Gruppe bereits 43 Jahre, insgesamt lag jedoch das Alter der Patienten ohne Jodexposition nicht signifikant niedriger.

Obwohl die Verlaufsbeobachtungen zeigten, daß die überwiegende Zahl der Patienten mit jodinduzierter Hyperthyreose (67\%) nur eine milde Symptomatik entwickelte, sind die Folgen einer Jodkontamination nicht im voraus abschätzbar und können für einen Teil der $\mathrm{Be}$ troffenen eine vitale Gefährdung darstellen. Auch von anderer Seite ist wiederholt auf diese besondere Verlaufsform hingewiesen worden, die in Einzelfällen Intensivmaßnahmen einschließlich Plasmapherese erfordert (9, 24). Aus diesen Gründen erscheint der Nachweis oder aber Ausschluß einer Jodkontamination bei jeder Hyperthyreose notwendig. Bei allen unseren 27 Patienten konnte eine vorangegangene Jodbelastung bereits durch die anamnestischen Angaben zweifelsfrei diagnostiziert werden. In $78 \%$ wurde sie auch durch eine erhöhte freie Jodkonzentration im Serum bestätigt. Darüber hinaus hat die Höhe des Jods im Serum prognostische Bedeutung. Drei bis 5 Wochen nach Abfall der Jodkonzentration in den Normbereich kann mit einer Normalisierung der Schilddrüsenfunktion gerechnet werden. Zu diesem Zeitpunkt kann daher eine bis dahin erforderliche thyreostatische Behandlung risikolos beendet werden. Die Verlaufsbeobachtung des Jodspiegels im Serum ergibt somit Anhaltspunkte für die angemessene Dauer einer Behandlung mit Thyreostatika, insbesondere bei Patienten, die unter Medikation eine klinische und hormonelle Euthyreose aufweisen. Man sollte daher bei jedem hyperthyreoten Patienten mit anamnestischer Jodexposition eine Gesamtjodbestimmung im Serum mit Berechnung des freien Jodanteils durchführen, wobei Gesamtjodwerte über $20 \mu \mathrm{g} / \mathrm{dl}$ praktisch beweisend für eine Jodkontamination sind. Erhöhte Werte bedürfen bis zu ihrer Normalisierung einer wiederholten Kontrolle. Auch wenn im Beobachtungszeitraum nach Abbruch der Thyreostatikatherapie keine Rezidive auftraten, können in Einzelfällen, wie z.B. beim autonomen Adenom der Schilddrüse, anschließend ablative Maßnahmen wie Radiojodtherapie oder subtotale Strumektomie indiziert sein.

\section{Anmerkung:}

Die Bestimmung von $\mathrm{T}_{4}, \mathrm{~T}_{3}$ und TSH erfolgte im Bereich Endokrinologie und Stoffwechsel (Prof. Dr. W. Vogt) des Instituts für Klinische Chemie (Direktor: Prof. Dr. M. Knedel), Klinikum Großhadern der Universität München.

Das Gesamtjod im Serum wurde im Institut für Labormedizin (Dr. V. Simkovic, München) gemessen.

Die Ergebnisse wurden zum Teil auf dem 28. Symposion der Deutschen Gesellschaft für Endokrinologie in Heidelberg, 7.-10. März 1984, vorgetragen.
Schrifttum:

1. COINDET, J. F.: Découverte d'une remède contre le goitre. Bibliothèque Universelle des Sciences et Belles Lettres Arts 14, 190 (1820).

2. COINDET, J. F.: Nouvelles récherches sur les effets de l'iode et sur les précautions à suivre dans le traitment du goitre par ce nouveau remède. Bibliothèque Universelles des Sciences et Belles Lettres Arts 36, 140 (1821).

3. ADAMS, D. D., KENNEDY, T. H., STEWART, J. C., UTIGER, R. D., VIDOR, G. I. Hyperthyroidism in Tasmania Following lodide Supplementation: Measurements of Thyroid-Stimulating Autoantibodies and Thyrotropin. J. Clin. Endocrinol. Metab. 41, 221-228 (1975)

4. CONNOLLY, R. I., VIDOR, G. I., STEWART, J. C.: Increase in Thyrotoxicosis in Endemic Goitre Area after lodination in Bread. Lancet, 500-502 (1970).

5. STEWART, J. C., VIDOR, G. I.: Thyrotoxicosis Induced by lodine Contamination of Food - a Common Unrecognised Condition? British Medical Journal 1, 372-375 (1976)

6. MILLER, J. M., HORN, R. C., BLOCK, M. A.: Autonomous Functioning Thyroid Nodule in the Evolution of Nodular Goiter. J. Clin. Endocrinol. Metab. 27, 12641274 (1967).

7. STUDER, H., HUNZIKER, H. R., RUCHTI, C.: Morphologic and Functional Substrate of Thyrotoxicosis Caused by Nodular Goiter. Am. J. Med. 65, 227-234 (1978) 8. STUDER, H., RAMELLI, P.: Simple Goiter and its Variants: Euthyroid and Hyperthyroid Multinodular Goiter. Endocrinol Rev. 3, 40 (1982).

9. HERRMANN, J., EMRICH, D., KEMPER, F., KOBBERLING, J., PICKARDT, R. C STUBBE, P.: Jodexzeß und seine Auswirkungen. Dtsch. Med. Wschr. 109, $1077-$ 1080 (1984).

10. HABERMANN, J., LEISNER, B., WITTE, A., PICKARDT, C. R., SCRIBA, P. C.: lodine Contamination as a Cause of Hyperthyroidism or Lack of TSH Response to TRH Stimulation. J. Endocrinol. Invest. 5, 153-156 (1982)

11. SCHICHA, H., EMRICH, D.: Immunogene und nicht immunogene Hyperthyreosen. Dtsch. Med. Wschr. 108, 6-11 (1983)

12. JOSEPH, K., MAHLSTEDT, J.: Thyreoidale Autonomie - Altersverteilung und Verhalten unter Jodprophylaxebedingungen. Nuc. Compact 10, 100-107 (1979)

13. PICKARDT, C. R.: Jodinduzierte Hyperthyreose. Dtsch. Med. Wschr. 107, 12191221 (1982)

14. JOSEPH, K.: Autonomes Schilddrüsengewebe - Früherkennung, Prognose und Verhalten unter Jodsalzprophylaxe. Krankenhausarzt 55, 556-568 (1982).

15. JOSEPH, K. MAHLSTEDT, J., GONNERMANN, R., HERBERT, K., WELSKE, U. Early Recognition and Evaluation of the Risk of Hyperthyroidism in Thyroid Autonomy in an Endemic Goiter Area. J. Molec. Med. 4. 21 (1980).

16. GREHN, S., STEIDLE, B., SEIF, F. J.: Änderung der Schilddrüsenfunktion nach jodhaltigen Röntgenkontrastmitteln bei Patienten aus einem endemischen Strumagebiet. Fortschr. Röntgenstr. 135/2, 151-156 (1981)

17. JAFFIOL, C., BALDET, L., BADA, M., VIERNE, Y.: The Influence on Thyroid Function of two lodine Containing Radiological Contrast Media. British J. of Radiology 55, 263-265 (1982)

18. STEIDLE, B., GREHN, S., SEIF, F. J.: Jodinduzierte Hyperthyreose durch Kontrastmittel. Disch. Med. Wschr. 104, 1435-1438 (1979).

19. EMRICH, D., KARKAVITSAS, N., FACORRO, U., SCHÜRNBRAND, P., SCHREIVOGEL, I., SCHICHA, H., DIRKS, H.: Influence of Increasing lodine Intake on Thyroid Function in Euthyroid and Hyperthyroid States. J. Clin. Endocrinol. Metab. 54, 12361241 (1982).

20. SOBRINHO, L. G., LIMBERT, E. S., SANTOS, M. A.: Thyroxine Toxicosis in Patients with lodine Induced Thyrotoxicosis. J. Clin. Endocrinol. Metab. 45, 25-29 (1977).

21. BÜRGI, H., WIMPFHEIMER, C., BURGER, A., ZAUNBAUER, W., RÖSLER, H., LEMARCHAND-BERAUD, Th. Changes of Circulating Thyroxine, Triiodothyronine and Reverse Triiodothyronine after Radiographic Contrast Agents. J. Clin. Endocrinol. Metab. 43, 1203-1211 (1976)

22. BURGER, A. G., LAMBERT, H.: Einfluß jodhaltiger Medikamente auf den Thyroxinmetabolismus. Akt. Endokr. Stoffw. 3, 13-14 (1982).

23. WU SY, CHOPRA, I. J., SOLOMON, D. H., BENNETT, L. R.: Changes in Circulating lodothyronines in Euthyroid and Hyperthyroid Subjects given Ipodate (Oragrafin) an Agent for Oral Cholecystography. J. Clin. Endocrinol. Metab. 46, 691-697 (1978) 24. HERRMANN, J., KRÜSKEMPER, H. L.: Gefährdung von Patienten mit latente und manifester Hyperthyreose durch jodhaltige Röntgenkontrastmittel und Medikamente. Dtsch. Med. Wschr. 103, 1434-1443 (1978)

Anschrift des Verfassers:

PD Dr. med. Dieter Jüngst

Medizinische Klinik 2

Klinikum Großhadern der Universität

Marchioninistr. 15

8000 München 70 